\title{
Comparison of Clinical Outcomes of Intracranial Aneurysms: Procedural Rupture versus Spontaneous Rupture
}

\author{
(D)H.H. Choi, (DE.J. Ha, (D).J. Lee, DD.H. Yoo, DW.-S. Cho, DJ.E. Kim, (DY.D. Cho, (DM.H. Han, and (DH.-S. Kang
}

\begin{abstract}
BACKGROUND AND PURPOSE: Procedural rupture of an intracranial aneurysm is a devastating complication in endovascular treatment. The purpose of this study was to evaluate the clinical outcomes of patients with procedural rupture of unruptured saccular intracranial aneurysms compared with those with spontaneously ruptured aneurysms.
\end{abstract}

MATERIALS AND METHODS: A retrospective review was performed for 1340 patients with 1595 unruptured saccular intracranial aneurysms that underwent endovascular coil embolization between February 2010 and December 2014. The clinical outcomes of patients with procedural rupture of unruptured saccular intracranial aneurysms were compared with those of 198 patients presenting with spontaneously ruptured aneurysms.

RESULTS: In this series, procedural rupture developed in 19 patients (1.4\% per patient and $1.2 \%$ per aneurysm), and the morbidity related to procedural rupture was $26.3 \%$ (95\% confidence interval, $8.5 \%-61.4 \%$ ) with no mortality. Hunt and Hess scale grades and hospitalization days of patients with procedural rupture were equivalent to those of patients presenting with spontaneous aneurysm rupture. Subsequent treatment procedures after hemorrhage (including lumbar drainage, extraventricular drainage, decompressive craniectomy, and permanent shunt) showed no difference between the 2 groups. The hemorrhage volumes were smaller in the procedural-rupture group ( $P=.03)$, and the endovascular vasospasm therapies tended to be more frequently required in the spontaneous aneurysm-rupture group $(P=.08)$. At postictus 6 months, the proportion of modified Rankin Scale scores of $\geq 2$ were lower in the procedural-rupture group (5.3\% versus $26.8 \%, P=.049)$. In multivariate analysis, spontaneous aneurysm rupture was a significant risk factor for worse clinical outcome (OR = 14.9; $95 \% \mathrm{Cl}, 1.2-193.1 ; P=.039)$.

CONCLUSIONS: This study showed better clinical outcomes in the procedural-rupture group. Even though there is a potential chance of aneurysm rupture during treatment, the clinical outcomes after procedural bleeds seem to be more favorable than those of spontaneous rupture.

ABBREVIATIONS: $\mathrm{PR}=$ procedural rupture; $\mathrm{SR}=$ spontaneous aneurysm rupture; $\mathrm{UIA}=$ unruptured saccular intracranial aneurysm

E ndovascular coil embolization for intracranial aneurysms is a recent development that is gradually replacing surgical clipping because of attributes that include minimal invasiveness and lower rates of morbidity and mortality. ${ }^{1,2}$ Nevertheless, procedural rupture (PR) of an aneurysm being treated remains a devastating complication in endovascular treatment. Although the incidence, risk factors, and clinical outcome of PR have been pre-

Received March 28, 2017; accepted after revision June 9.

From the Departments of Neurosurgery (H.H.C.), Dongguk University College of Medicine, Dongguk University Hospital, Ilsan, Korea; and Departments of Neurosurgery (E.J.H., W.-S.C., J.E.K., H.-S.K.) and Radiology (.J.L., D.H.Y., Y.D.C, M.H.H.), Seoul National University College of Medicine, Seoul National University Hospital, Seoul, Korea.

Please address correspondence to Hyun-Seung Kang, MD, PhD, Department of Neurosurgery, Seoul National University College of Medicine, Seoul National University Hospital, 101 Daehak-ro, Jongno-gu, Seoul 03080, Korea; e-mail: hsk4428@yahoo.com

http://dx.doi.org/10.3174/ajnr.A5344 viously reported, ${ }^{1,3-9}$ the clinical prognosis of pure PR remains unclear because the reports included ruptured aneurysms, hindering the assessment of the harmful influence of PR. In addition, there have been various treatment guidelines in unruptured intracranial aneurysms (UIAs), ${ }^{10-14}$ and some argue that no treatment might be cost-effective in some clinical situations. ${ }^{10,15,16}$ In principle, the treatment decision should be made on the basis of treatment benefit and its accompanying risks in comparison with the disease burden. The purpose of this study was to assess the clinical outcomes of patients with PR of UIAs compared with those with spontaneously ruptured aneurysms.

\section{MATERIALS AND METHODS Patient Characteristics}

From February 2010 to December 2014, 2025 aneurysms in 1711 patients were treated with endovascular procedures at a 
single tertiary care institution (Seoul National University Hospital). Of these, 232 aneurysms were excluded from statistical analysis; they were retreated, dissecting, blisterlike, or false aneurysms. Thus, we intended to analyze the clinical outcomes of PR in saccular aneurysms treated with detachable coil embolization. The study cohort included 1531 patients with 1793 saccular aneurysms treated in 1538 sessions. Among them, 198 patients presented with subarachnoid hemorrhage. There were $455(29.7 \%)$ male and 1076 (70.3\%) female patients with a mean age of 55.8 years (median, 59 years; range, $13-89$ years) at the time of the procedure. The procedural rupture occurred in $1.2 \%$ per aneurysm (19/1595) among patients with unruptured aneurysms. We compared the clinical outcomes of the 19 patients (PR group) with those of 198 patients with spontaneously ruptured aneurysms (SR group). This study was conducted according to the principles outlined in the Declaration of Helsinki and was approved by the institutional review board.

\section{Treatment}

The endovascular treatment technique was properly selected under the consensus of the cerebrovascular team in a multidisciplinary decision-making process with consideration of the patient's preference. The coiling of aneurysms was performed mostly with the patient under general anesthesia. For these patients with unruptured aneurysms, preprocedural medication with antiplatelet agents was provided. Systemic administration of heparin was performed after deployment of an arterial introducer sheath in unruptured aneurysms and after placement of the first coil in ruptured aneurysms with a bolus dose of 3000 IU followed by a maintenance dose of 1000 IU per hour with monitoring of the activated clotting time. Several kinds of detachable coils, chosen by the operator, were used. Coil placement proceeded until optimal satisfactory aneurysm obliteration was achieved.

Procedural rupture was diagnosed by the extravasation of contrast and direct visualization of a device outside the aneurysm lumen on cerebral angiography. When PR occurred, protamine sulfate was administered immediately to reverse the effects of heparin and coils were deployed quickly to occlude the aneurysm. After the embolization, a CT scan was performed to evaluate the amount of subarachnoid hemorrhage and the development of hydrocephalus. Depending on the patient's neurologic condition, further intervention ensued, which included lumbar drainage, extraventricular drainage, or decompressive surgery. Endovascular vasospasm therapy was performed when the patients showed neurologic deterioration with angiographic vasospasm during the ensuing days.

\section{Clinical Variables and Outcomes}

All the relevant medical records were reviewed, including data regarding patient age, sex, aneurysm location, maximal aneurysm diameter, applied endovascular treatment technique, Hunt and Hess scale grade, ${ }^{17}$ modified Fisher grade,${ }^{18}$ hospitalization days, and clinical outcome. The treatment procedural data, including lumbar drainage, extraventricular drainage, decompressive crani-
Table 1: Comparison of patient characteristics

\begin{tabular}{lccc}
\hline & $\begin{array}{c}\text { PR Group } \\
(\boldsymbol{n}=19)\end{array}$ & $\begin{array}{c}\text { SR Group } \\
(\boldsymbol{n}=198)\end{array}$ & $\begin{array}{c}\boldsymbol{P} \\
\text { Value }\end{array}$ \\
\hline Female & $16(84.2 \%)$ & $116(58.6 \%)$ & $.047^{\mathrm{a}}$ \\
Mean age (yr) & $53.6 \pm 1.5$ & $55.8 \pm 1.0$ & .22 \\
Mean aneurysm size (mm) & $4.6 \pm 0.5$ & $6.5 \pm 0.2$ & $.01^{\mathrm{a}}$ \\
Aneurysm location & & & .15 \\
$\quad$ Anterior cerebral artery & $4(21.1 \%)$ & $93(47.0 \%)$ & \\
Middle cerebral artery & $5(26.3 \%)$ & $35(17.7 \%)$ & \\
Internal carotid artery & $9(47.4 \%)$ & $57(28.8 \%)$ & \\
Posterior circulation & $1(5.2 \%)$ & $13(6.5 \%)$ & \\
Hunt and Hess scaleb & & & .82 \\
1 & $1(5.3 \%)$ & $7(3.5 \%)$ & \\
2 & $13(68.4 \%)$ & $123(62.1 \%)$ & \\
3 & $2(10.5 \%)$ & $36(18.2 \%)$ & \\
4 & $3(15.8 \%)$ & $26(13.1 \%)$ & \\
5 & $0(0 \%)$ & $6(3.1 \%)$ & \\
Modified Fisher grade & & & $.03^{\mathrm{a}}$ \\
Small volume (grade 1) & $14(73.7 \%)$ & $89(45.0 \%)$ & \\
Large volume (grades 2-4) & $5(26.3 \%)$ & $109(55.0 \%)$ & \\
\hline
\end{tabular}

a Significant.

${ }^{b}$ Hunt and Hess scale grades were immediately assessed after the patient recovered from the anesthesia in the PR group and at admission in the SR group without adjustment of comorbidity.

ectomy, endovascular vasospasm therapy, and ventriculoperitoneal shunt, were also collected.

Aneurysm size was measured on the basis of 3D reconstruction angiograms. Follow-up angiographic results were evaluated with the last follow-up digital subtraction angiography and/or MR angiography. The results were divided into 2 categories: stable occlusion and recanalization.

Hunt and Hess scale grades were immediately assessed after recovery from anesthesia in the PR group and were assessed on admission in the SR group. Adjustments were not made for comorbidities. The modified Fisher grades were denoted and then were categorized into 2 groups: small hemorrhage volume (grade 1) and large volume (grades 2-4). Clinical outcome was evaluated with the modified Rankin Scale scores, and poor functional outcome was defined as an mRS score of $\geq 2$ at postictus 6 months. ${ }^{19}$ When 6-month mRS scores were not recorded, the score nearest to 6 months was used in the analysis.

\section{Statistical Analysis}

Continuous variables were expressed as the mean \pm SD (range). $\chi^{2}$, Fisher exact, and Student $t$ tests were performed as necessary. A binary logistic regression model was used to ensure that procedural or spontaneous aneurysm rupture was independently predictive of clinical outcomes. Log-rank tests were used to compare time to aneurysm recanalization. A 2-tailed $P$ value $<.05$ was considered statistically significant. The data were analyzed with the Statistical Package for the Social Sciences (Version 21; IBM, Armonk, New York) and MedCalc for Windows, Version 14.12.0 (MedCalc Software, Ostend, Belgium).

\section{RESULTS}

\section{Enrolled Patients and Aneurysms}

The patient characteristics are shown in Table 1. There was a somewhat higher proportion of female patients in the PR group (PR versus SR group, $84.2 \%$ versus $58.6 \%$; $P=.047$ ). Mean aneurysmal size was larger in the SR group (6.5 versus $4.6 \mathrm{~mm}, P=$ 
$.01)$. The most frequent aneurysm location was the internal carotid artery $(47.4 \%)$ in the PR group and the anterior cerebral artery in the SR group (47.0\%).

The distribution of Hunt and Hess scale grades was not significantly different between the 2 groups. The hemorrhage volume, determined by modified Fisher grade, was larger in the SR group $(P=.03)$. Most $(73.7 \%)$ in the PR group showed grade 1 bleeds, while more than half of the patients in the SR group presented with higher than grade 1 bleeds.

Table 2: Comparison of embolization techniques and treatment procedures $^{\mathrm{a}}$

\begin{tabular}{|c|c|c|c|}
\hline & $\begin{array}{l}\text { PR Group } \\
(n=19)\end{array}$ & $\begin{array}{l}\text { SR Group } \\
(n=198)\end{array}$ & $\begin{array}{c}P \\
\text { Value }\end{array}$ \\
\hline Technique & & & $<.01^{\mathrm{b}}$ \\
\hline Single microcatheter & $12(63.2 \%)$ & $108(54.6 \%)$ & \\
\hline Double microcatheter & $2(10.4 \%)$ & $65(32.8 \%)$ & \\
\hline Balloon remodeling & $4(21.1 \%)$ & $5(2.5 \%)$ & \\
\hline Stent-assisted & $1(5.3 \%)$ & $20(10.1 \%)$ & \\
\hline Lumbar drainage & & & .23 \\
\hline Yes & $6(31.6 \%)$ & $38(19.2 \%)$ & \\
\hline No & $13(68.4 \%)$ & $160(81.2 \%)$ & \\
\hline Extraventricular drainage & & & .32 \\
\hline Yes & $1(5.3 \%)$ & 34 (17.2\%) & \\
\hline No & $18(94.7 \%)$ & $164(82.8 \%)$ & \\
\hline Decompressive craniectomy & & & 1.00 \\
\hline Yes & $0(0 \%)$ & $4(2.0 \%)$ & \\
\hline No & $19(100 \%)$ & $194(98.0 \%)$ & \\
\hline Endovascular vasospasm therapy & & & .08 \\
\hline Yes & $0(0 \%)$ & $32(16.2 \%)$ & \\
\hline No & $19(100 \%)$ & $166(83.8 \%)$ & \\
\hline Permanent shunt & & & 1.00 \\
\hline Yes & $1(5.3 \%)$ & $19(9.6 \%)$ & \\
\hline No & $18(94.7 \%)$ & $179(90.4 \%)$ & \\
\hline
\end{tabular}

${ }^{a}$ Data are No. (\%) unless otherwise indicated.

${ }^{\mathrm{b}}$ Significant.

Table 3: Comparison of clinical outcome and imaging follow-up

\begin{tabular}{lccl}
\hline & $\begin{array}{c}\text { PR Group } \\
(\boldsymbol{n}=19)\end{array}$ & $\begin{array}{c}\text { SR Group } \\
(\boldsymbol{n}=198)\end{array}$ & $\begin{array}{c}\boldsymbol{P} \\
\text { Value }\end{array}$ \\
\hline Mean hospitalization (day) & $13.7 \pm 3.1$ & $18.4 \pm 1.2$ & .25 \\
Compromised outcome ${ }^{\mathrm{a}}$ (No.) & $1(5.3 \%)$ & $53(26.8 \%)$ & $.049^{\mathrm{b}}$ \\
Follow-up imaging (No.) & & & \\
$\quad$ Recanalization & $1(5.3 \%)$ & $40(20.2 \%)$ & \\
$\quad$ Stable & $14(73.6 \%)$ & $122(61.7 \%)$ & \\
$\quad$ Absence of follow-up imaging & $4(21.1 \%)$ & $36(18.1 \%)$ & \\
\hline
\end{tabular}

a Modified Rankin Scale scores of $\geq 2$ at postictus 6 months.

b Significant.
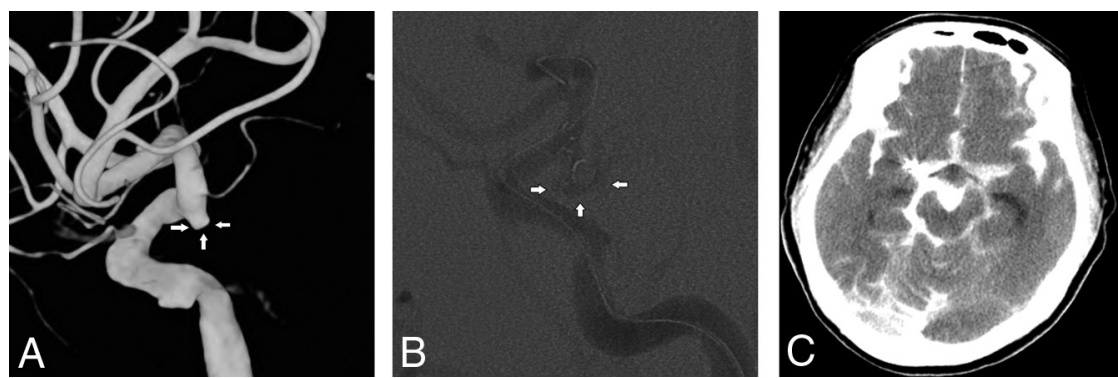

FIG 1. Cerebral angiography demonstrates a right posterior communicating artery aneurysm $(A)$. During coil embolization with balloon remodeling, the aneurysm was ruptured by a coil $(B)$. Despite rapid obliteration of the ruptured aneurysm, the volume of subarachnoid hemorrhage was considerable (modified Fisher grade 3) (C).

\section{Procedural Characteristics}

The endovascular procedures and subsequent interventions are presented in Table 2. The embolization techniques were significantly different between the 2 groups $(P<.01)$; notably, the balloon-remodeling technique was more frequently used in the PR group (PR group versus SR group, $21.1 \%$ versus $2.5 \%$; $P<.01$ ). The culprit devices causing procedural aneurysmal rupture were coils in most cases $(n=17,89.5 \%)$, and the remaining devices were microcatheters $(n=2,10.5 \%)$.

The procedures subsequent to the coil embolization were not significantly different between the 2 groups (Table 2), except that more patients tended to require endovascular vasospasm therapy in the SR group (PR group versus SR group, $0 \%$ versus $16.2 \% ; P=$ $.08)$. On further analysis, the patients with larger hemorrhage volume required endovascular vasospasm therapy more frequently (modified Fisher grade 1 versus grades $2-4$, 8.7\% versus 20.2\%, $P=.02)$.

\section{Clinical Outcomes}

All 19 patients in the PR group were asymptomatic before PR. Headache without neurologic symptoms was the most common symptom following PR $(n=13,68.4 \%)$, followed by motor weakness $(n=3,15.8 \%)$, diplopia $(n=1)$, and altered mentality $(n=$ 1). One patient was asymptomatic despite PR. The hospitalization days of the PR group were 13.7 days on average (median, 12 days; range, 3-63 days), which did not differ significantly from those patients in the SR group (mean, 18.4 days; median, 15 days: range, 3-209 days) $(P=.25)$ (Table 3$)$.

In the $\mathrm{PR}$ group, there were 5 patients with morbidity $(26.3 \%$; $95 \%$ confidence interval, $8.5 \%-61.4 \%)$ and no mortality. Compromised clinical outcome (defined as an mRS score of $\geq 2$ ) at the 6-month follow-up evaluation was found in 1 patient (5.3\%) in the PR group, whose mRS score was 4 (Fig 1). The other 18 patients did not have any associated symptoms at postictus 6 months. In the SR group, compromised clinical outcomes were found in 53 patients $(26.8 \%)$, which was a significantly higher rate in comparison with that in the PR group $(P=.049)$ (Fig 2). Multivariate analysis indicated that spontaneous aneurysm rupture was one of independent risk factors for poor clinical outcome $(\mathrm{OR}=14.9 ; 95 \% \mathrm{CI}, 1.2-193.1 ; P=.039)$, along with patient age, Hunt and Hess scale grade, and the amount of bleed as measured by the modified Fisher grade (Table 4).

Follow-up angiographic images were available in 15 patients (78.9\%) in the PR group and in $162(81.8 \%)$ in the SR group. One of the 15 patients $(6.7 \%)$ had recanalization in the PR group, and 40 (20.2\%) had recanalization in the SR group $(P=.064)$. Kaplan-Meier estimates of the rates of stable aneurysmal occlusion are presented in Fig 3.

\section{DISCUSSION}

In our study, 1340 patients with 1595 UIAs were treated with endovascular coil embolization. The risk of PR was low (1.4\% per patient and $1.2 \%$ per aneurysm), like that in previous studies that reported a $0 \%$ $2.2 \%$ rate of PR in UIAs. ${ }^{1-3,5,7}$ The PR-re- 
lated symptomatic complication rate was $0.1 \%$ ( 1 of 1340) in clinical assessment at 6 months after ictus. The hospitalization days and Hunt and Hess scale grades did not differ significantly between the 2 groups. However, the proportion of patients with small hemorrhage volume (modified Fisher grade 1) was greater, and endovascular vasospasm therapies were less frequently required in the PR group. Accordingly, the clinical outcomes in the patients with PR of UIAs were more favorable compared with those of the patients presenting with spontaneously ruptured aneurysms. Although we cannot choose between spontaneous SAH and intraoperative rupture, physicians may inform patients with UIAs of expected clinical outcomes of PR before decision-making for the treatment.

Many neurointerventionists are concerned about PR. Various factors, including size, location, and morphology of aneurysms and a previous rupture history, have been analyzed to evaluate the risk factors of PR. ${ }^{1,3-9}$ A multicenter study reported increased periprocedural death or disability in $63 \%$ of patients with $\mathrm{PR}$ compared with $15 \%$ without $\mathrm{PR},{ }^{20}$ and another study reported a $33 \%$ risk of death and 5\% risk of disability with PR in ruptured aneurysms. ${ }^{21}$ However, the clinical outcome for PR of UIAs is not well-described because of the limited number of cases. ${ }^{1,6,22,23}$ Concerning unruptured aneurysms, Im et $\mathrm{al}^{2}$ and Schuette et $\mathrm{al}^{5}$ reported 4 cases and 1 case of $P R$, respectively; there was no mortality or morbidity, but the number of cases was too small to conclude a reliable clinical outcome. Mitchell et $\mathrm{al}^{7}$ reported higher rates of 30-day mortality with PR of UIAs (1 of 6, 16.7\%) than in patients without PR ( 2 of $249,0.8 \%$ ). In the present study, there were 5 cases of morbidity but no mortality in the 19 PR cases treated for unruptured aneurysms. At 6 months after ictus, only 1 of 1340 patients $(0.1 \%)$ had poor mRS scores $(>2)$ related to $P R$.

The clinical outcome of PR seems to have 1 of 2 extremes: death or recovery. ${ }^{22}$ Sluzewski et al ${ }^{22}$ reported 20 deaths and 31 good outcomes in 51 procedure-related ruptures; most patients (97.4\%) were treated after rupture. Of the 19 patients with PR in our series, 5 had neurologic symptoms such as weakness or altered mentality, and 14 patients had headache only on the immediate neurologic examina-

\section{PR GROUP}

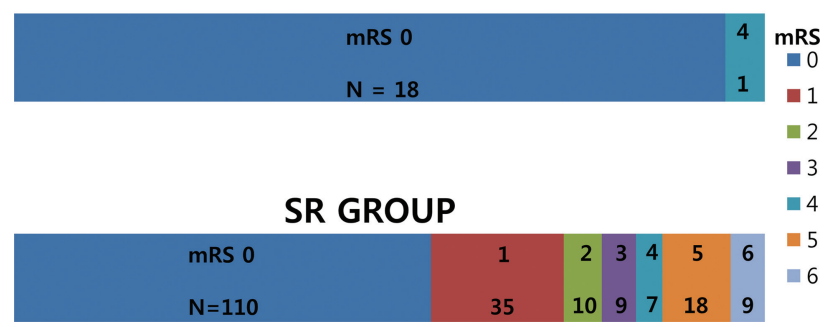

FIG 2. Modified Rankin Scale scores at the 6-month posttreatment period. tion after PR. In the 5 symptomatic patients, only 1 patient had permanent hemiparesis, and 4 patients fully recovered without neurologic sequelae. Unlike those with ruptured aneurysms, the patients with PR of UIAs had favorable functional outcomes and did not have fatal outcomes. The favorable results in PR of UIAs might be due to the rapid obliteration of the aneurysm to prevent massive hemorrhage when PR occurs during coil embolization. When the PR occurred, additional coils were deployed promptly, sometimes in conjunction with a balloon or a stent to control leakage. Symptomatic vasospasm after aneurysmal SAH occurred in $16.2 \%$ of patients with spontaneously ruptured aneurysms, comparable with reported rates of $17 \%-40 \% .^{24}$ Notably, the patients with PR did not present with symptomatic vasospasm in any case in our series. We believe that the rapid obliteration of PR leads to less hemorrhage volume, no symptomatic vasospasm, and more favorable clinical outcomes.

Stapleton et $\mathrm{al}^{9}$ reported an increased risk of symptomatic hydrocephalus requiring temporary or permanent cerebral fluid diversion with rerupture of ruptured intracranial aneurysms. In our study, treatment procedures after rupture were not significantly different between the PR and SR groups, including lumbar drainage, extraventricular drainage, decompressive craniectomy, and permanent ventricular shunt.

In the present study, the balloon remodeling technique was used less often in the SR group than in the PR group. Several multicenter studies reported that balloon-remodeling coil embolization was not

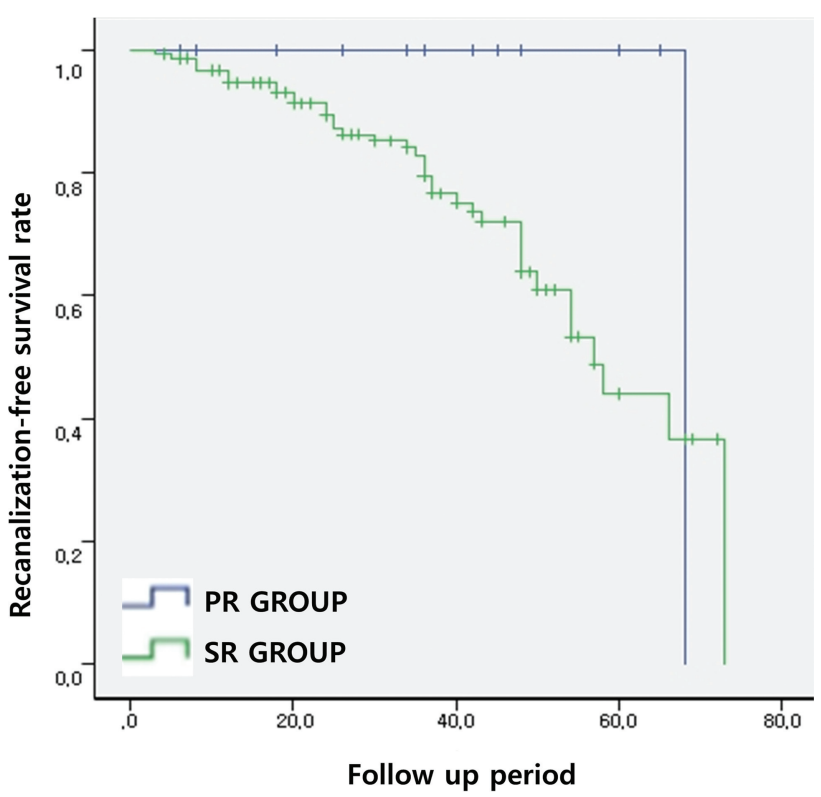

FIG 3. Kaplan-Meier estimates of the rates of stable aneurysmal occlusion: procedural rupture group versus spontaneous rupture group.

Table 4: Logistic regression model assessing risk factors of poor clinical outcome

\begin{tabular}{|c|c|c|c|c|c|c|}
\hline \multirow[b]{2}{*}{ Variables } & \multicolumn{3}{|c|}{ Univariate Analysis } & \multicolumn{3}{|c|}{ Multivariate Analysis } \\
\hline & Odds Ratio & $95 \% \mathrm{Cl}$ & $P$ Value & Odds Ratio & $95 \% \mathrm{Cl}$ & $P$ Value \\
\hline Age & 1.051 & $1.024-1.079$ & $.000^{\mathrm{a}}$ & 1.053 & $1.020-1.087$ & $.001^{\mathrm{a}}$ \\
\hline Sex & 1.016 & $0.541-1.909$ & .961 & - & - & - \\
\hline Hunt and Hess scale grade & 4.874 & $3.075-7.725$ & $.000^{\mathrm{a}}$ & 4.565 & $2.608-7.989$ & $.000^{\mathrm{a}}$ \\
\hline Modified Fisher grade & 9.868 & $4.203-23.167$ & $.000^{\mathrm{a}}$ & 2.867 & $1.053-7.809$ & $.039^{a}$ \\
\hline SR & 6.579 & $0.857-50.503$ & $.070^{a}$ & 14.908 & 1.151-193.054 & $.039^{a}$ \\
\hline
\end{tabular}

Note:- - indicates variable was not included in the multivariate analysis.

a Significant. 
related to an increase in $\mathrm{PR}^{25,26}$ In contrast, Sluzewski et $\mathrm{al}^{27}$ reported a high complication rate with balloon-remodeling coil embolization. The increased risk of PR during balloon-remodeling coil embolization is still debated. ${ }^{25,28-30}$

This study has limitations inherent in a single-institution retrospective study. Therefore, the results should be viewed considering the statistical constraint resulting from the limited number of patients with PR. A multicenter study with a larger number of cases is needed to confirm the results.

\section{CONCLUSIONS}

The patients with PR of UIAs had less hemorrhage volume with lower modified Fisher grades and underwent endovascular vasospasm therapy less frequently than those with SR. Accordingly, clinical outcomes of these patients were more favorable. Patients with PR of UIAs can recover well if rapid obliteration of the aneurysm and subsequent appropriate management are undertaken.

Disclosures: Moon Hee Han—UNRELATED: Consultancy: MicroVention*. *Money paid to the institution.

\section{REFERENCES}

1. Brisman JL, Niimi Y, Song JK, et al. Aneurysmal rupture during coiling: low incidence and good outcomes at a single large volume center. $\mathrm{Neu}$ rosurgery 2005;57:1103-09; discussion 1103-09 CrossRef Medline

2. Im SH, Han MH, Kwon OK, et al. Endovascular coil embolization of 435 small asymptomatic unruptured intracranial aneurysms: procedural morbidity and patient outcome. AJNR Am J Neuroradiol 2009;30:79-84 Medline

3. Li MH, Gao BL, Fang C, et al. Prevention and management of intraprocedural rupture of intracranial aneurysm with detachable coils during embolization. Neuroradiology 2006;48:907-15 CrossRef Medline

4. Nguyen TN, Raymond J, Guilbert F, et al. Association of endovascular therapy of very small ruptured aneurysms with higher rates of procedure-related rupture. J Neurosurg 2008;108:1088-92 CrossRef Medline

5. Schuette AJ, Hui FK, Spiotta AM, et al. Endovascular therapy of very small aneurysms of the anterior communicating artery: five-fold increased incidence of rupture. Neurosurgery 2011;68:731-37; discussion 737 CrossRef Medline

6. Santillan A, Gobin YP, Greenberg ED, et al. Intraprocedural aneurysmal rupture during coil embolization of brain aneurysms: role of balloon-assisted coiling. AJNR Am J Neuroradiol 2012;33:2017-21 CrossRef Medline

7. Mitchell PJ, Muthusamy S, Dowling R, et al. Does small aneurysm size predict intraoperative rupture during coiling in ruptured and unruptured aneurysms? J Stroke Cerebrovasc Dis 2013;22:1298-303 CrossRef Medline

8. Zhang Y, Li G, Cai Y, et al. Rupture during the endovascular treatment of intracranial aneurysms: outcomes and technical aspects. Acta Neurochir (Wien) 2013;155:569-77 CrossRef Medline

9. Stapleton CJ, Walcott BP, Butler WE, et al. Neurological outcomes following intraprocedural rerupture during coil embolization of ruptured intracranial aneurysms. J Neurosurg 2015;122:128-35 CrossRef Medline

10. Komotar RJ, Mocco J, Solomon RA. Guidelines for the surgical treatment of unruptured intracranial aneurysms: the first annual J Lawrence Pool memorial research symposium-controversies in the management of cerebral aneurysms. Neurosurgery 2008;62:18393; discussion 193-94 CrossRef Medline

11. Thompson BG, Brown R Jr, Amin-Hanjani S, et al; American Heart Association Stroke Council, Council on Cardiovascular and Stroke Nursing, and Council on Epidemiology and Prevention, American Heart Association, American Stroke Association. Guidelines for the Management of Patients with Unruptured Intracranial Aneurysms: A Guideline for Healthcare Professionals from the American Heart Association/American Stroke Association. Stroke 2015;46:2368-400 CrossRef Medline
12. Steiner T, Juvela S, Unterberg A, et al. European Stroke Organization. European Stroke Organization guidelines for the management of intracranial aneurysms and subarachnoid haemorrhage. Cerebrovasc Dis 2013;35:93-112 CrossRef Medline

13. Burns JD, Brown RD Jr. Treatment of unruptured intracranial aneurysms: surgery, coiling, or nothing? Curr Neurol Neurosci Rep 2009;9:6-12 CrossRef Medline

14. Raabe A, Seifert V, Schmiedek P, et al; American Heart Association, Section of Vascular Neurosurgery of the German Society of Neurosurgery. Recommendations for the management of unruptured intracranial aneurysms [in German]. Zentralbl Neurochir 2002;63:70-76 CrossRef Medline

15. Greving JP, Rinkel GJ, Buskens E, et al. Cost-effectiveness of preventive treatment of intracranial aneurysms: new data and uncertainties. Neurology 2009;73:258-65 CrossRef Medline

16. Brown RD Jr, Broderick JP. Unruptured intracranial aneurysms: epidemiology, natural history, management options, and familial screening. Lancet Neurol 2014;13:393-404 CrossRef Medline

17. Hunt WE, Hess RM. Surgical risk as related to time of intervention in the repair of intracranial aneurysms. J Neurosurg 1968;28:14-20 CrossRef Medline

18. Frontera JA, Claassen J, Schmidt JM, et al. Prediction of symptomatic vasospasm after subarachnoid hemorrhage: the modified Fisher scale. Neurosurgery 2006;59:21-27; discussion 21-27 CrossRef Medline

19. van Swieten JC, Koudstaal PJ, Visser MC, et al. Interobserver agreement for the assessment of handicap in stroke patients. Stroke 1988; 19:604-07 CrossRef Medline

20. Elijovich L, Higashida RT, Lawton MT, et al; Cerebral Aneurysm Rerupture After Treatment (CARAT) Investigators. Predictors and outcomes of intraprocedural rupture in patients treated for ruptured intracranial aneurysms: the CARAT study. Stroke 2008;39:1501-06 CrossRef Medline

21. Cloft HJ, Kallmes DF. Cerebral aneurysm perforations complicating therapy with Guglielmi detachable coils: a meta-analysis. AJNR Am J Neuroradiol 2002;23:1706-09 Medline

22. Sluzewski M, Bosch JA, van Rooij WJ, et al. Rupture of intracranial aneurysms during treatment with Guglielmi detachable coils: incidence, outcome, and risk factors. J Neurosurg 2001;94: 238-40 CrossRef Medline

23. Tummala RP, Chu RM, Madison MT, et al. Outcomes after aneurysm rupture during endovascular coil embolization. Neurosurgery 2001;49:1059-66; discussion 1066-67 Medline

24. Charpentier C, Audibert G, Guillemin F, et al. Multivariate analysis of predictors of cerebral vasospasm occurrence after aneurysmal subarachnoid hemorrhage. Stroke 1999;30:1402-08 CrossRef Medline

25. Pierot L, Cognard C, Anxionnat R, et al. Remodeling technique for endovascular treatment of ruptured intracranial aneurysms had a higher rate of adequate postoperative occlusion than did conventional coil embolization with comparable safety. Radiology 2011; 258:546-53 CrossRef Medline

26. Pierot L, Spelle L, Vitry F. Immediate clinical outcome of patients harboring unruptured intracranial aneurysms treated by endovascular approach: results of the ATENA study. Stroke 2008;39:2497504 CrossRef Medline

27. Sluzewski M, van Rooij WJ, Beute GN, et al. Balloon-assisted coil embolization of intracranial aneurysms: incidence, complications, and angiography results. J Neurosurg 2006;105:396-99 CrossRef Medline

28. Levy E, Koebbe CJ, Horowitz MB, et al. Rupture of intracranial aneurysms during endovascular coiling: management and outcomes. Neurosurgery 2001;49:807-11; discussion 811-13 Medline

29. Pierot L, Spelle L, Leclerc X, et al. Endovascular treatment of unruptured intracranial aneurysms: comparison of safety of remodeling technique and standard treatment with coils. Radiology 2009;251: 846-55 CrossRef Medline

30. Pierot L, Cognard C, Spelle L, et al. Safety and efficacy of balloon remodeling technique during endovascular treatment of intracranial aneurysms: critical review of the literature. AJNR Am J Neuroradiol 2012;33:12-15 CrossRef Medline 